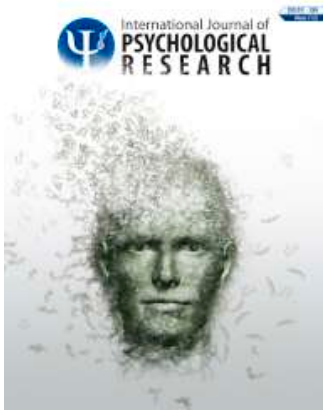

Vol $13, \mathrm{~N}^{\circ} 2$

https://revistas.usb.edu.co/index.php/IJPR ISSN 2011-2084

E-ISSN 2011-7922

\title{
An Exploratory Study for Assessment of Multimodal Semantic Memory in Colombian Children
}

\author{
Estudio exploratorio para la evaluación de la memoria semántica \\ multimodal en niños colombianos
}

\author{
María C. Navarro ${ }^{1}$ id, Fernando Marmolejo-Ramos ${ }^{2}$ io, \\ Valentina Vásquez ${ }^{1}$ id, Bárbara Carrea ${ }^{3}$ id Jorge I. Vélez $^{1}$ (i), \\ Moisés Mebarak Chams ${ }^{1 \star \text { iD }}$ \\ ${ }^{1}$ Universidad del Norte, Barranquilla, Colombia. \\ ${ }^{2}$ Center for Change and Complexity in Learning, The University of South Australia, \\ Adelaide, Australia. \\ ${ }^{3}$ Pontificia Universidad Javeriana, Bogotá, Colombia.
}

\begin{abstract}
.
Semantic memory (SM) is a type of long-term memory associated with the storage of general information about the world. Here we assessed the characteristics of the SM battery, developed by Catricalà et al. (2013), in a sample of Colombian children. This battery was originally conceived to evaluate adults, and features six subtests that assess SM in different modalities, using a common set of 48 stimuli in both living and nonliving categories. The design of the current study is of a cross-sectional and exploratory type. The sample was composed of 111 children, 57 boys $(51 \%)$ and 54 girls $(49 \%)$, who were $6(n=68)$ and $7(n=43)$ years old and had no intellectual disability. Robust linear regression models and correlation networks were used. We found an effect of age on general intelligence after correcting for gender, and no differences on the six subtest scores after corrections for gender and age were performed. Furthermore, age was found to be positively associated with the naming of colored photographs $(\beta=.75, p=.039)$, naming in response to an oral description $(\beta=1.81, p=.039)$, picture sorting at four levels $(\beta=7.22, p=.029)$, and sentence verification $(\beta=26.66, p=.01)$. In addition, there were differences between the results obtained in adults in the original study and in the children of our study. This exploratory study supports the feasibility of the Spanish translation of the Catricalà et al. (2013) battery to assess SM in children with a nonclinical condition. Future studies are needed to evaluate the psychometric properties of this SM battery, and to corroborate and expand our findings in a larger sample of control children, and in children with some degree of intellectual disability or suffering of some neurodegenerative or psychiatric conditions.

Resumen.

La memoria semántica (SM) es un tipo de memoria a largo plazo asociada con el almacenamiento de información general sobre el mundo. Aquí evaluamos las características de la batería SM, desarrollada por Catricalà et al. (2013), en una muestra de niños colombianos. Esta batería fue concebida originalmente para evaluar adultos, y presenta seis subpruebas que evalúan SM en diferentes modalidades, utilizando un conjunto común de 48 estímulos en las categorías de vida y no vida. El diseño del presente estudio es de tipo transversal y exploratorio. La muestra estaba compuesta por 111 niños, 57 niños (51\%) y 54 niñas (49\%), que tenían $6(n=68)$ y $7(n=43)$ años y no tenían discapacidad intelectual. Se utilizaron modelos de regresión lineal robustos y redes de correlación. Encontramos un efecto de la edad en la inteligencia general después de corregir por género, y no hubo diferencias en las seis puntuaciones de la subprueba después de realizar correcciones por género y edad. Además, se encontró que la edad se asociaba positivamente con el nombramiento de fotografías en color $(\beta=.75, p=.039)$, nombrando en respuesta a una descripción oral $(\beta=1.81, p=.039)$, clasificación de imágenes en cuatro niveles $(\beta=7.22, \mathrm{p}=.029)$ y verificación de oraciones $(\beta=26.66, p=.01)$. Además, hubo diferencias entre los resultados obtenidos en adultos en el estudio original y en los niños de nuestro estudio. Este estudio exploratorio respalda la viabilidad de la traducción al español de Catricalà et al. (2013) batería para evaluar SM en niños con una condición no clínica. Se necesitan estudios futuros para evaluar las propiedades psicométricas de esta batería SM, y para corroborar y expandir nuestros hallazgos en una muestra más grande de niños control, y en niños con algún grado de discapacidad intelectual o que padecen
\end{abstract}

^Corresponding author:

Email: mmebarak@uninorte.edu.co

Copyright: ๑2020. International Journal of Psychological Research provides open access to all its contents under the terms of the license creative commons AttributionNonCommercial-NoDerivatives 4.0 International (CC BY-NC-ND 4.0)

Declaration of data availability: All relevant data are within the article, as well as the information support files.

Conflict of interests: The authors have declared that there is no conflict of interest.

How to Cite:

Navarro, M. C., Marmolejo-Ramos, F., Vásquez, V., Correa, B., Vélez, J. I. \& Mebarak, M. (2020). An Exploratory Study for Assessment of Multimodal Semantic Memory in Colombian Children. International Journal of Psychological Research, 13(2), 4958. https://doi.org/10.21500/20112084.4847 algunas condiciones neurodegenerativas o psiquiátricas.

Keywords.

Memoria semántica; Assessment; Colombian Children; Neuropsychological evaluation. Palabras Clave.

Semantic Memory; Evaluación; Niños colombianos; Evaluación neuropsicológica. 


\section{Introduction}

Semantic memory (SM) is defined as a type of long-term memory associated with the storage of general information about the world, including knowledge of objects or concrete elements (Antonucci \& Reilly, 2008; Tulving, 1972, 1983, 1985; Tulving \& Craik, 2000). SM also includes concepts, and relationships, and it excludes procedural knowledge (De Vega, 2007; Diges \& Perpiñá, 2008).

Studies assessing SM are generally conducted in adult population and are related to cognitive impairment, Alzheimers disease or semantic dementia (Bozeat et al., 2000; Portin et al., 2000). However, the assessment of SM in children is considered relevant because SM has been shown to be related to acquisition of new learning (Bauera et al., 2020; Garrido et al., 2018; Wang et al., 2017). Robertson and Kohler (2007) have found that semantic competence in tasks associated with recognition memory tests in 4-6 years old children is a predictor of recognition performance, even if access to semantic information is not required. Furthermore, studies have found relationships between SM and some disorders. In particular, Gaye Vaurio (2004) found that the SM network in children with Attention Deficit Hyperactivity Disorder (ADHD) is less efficient than in children without ADHD, thus showing significantly less benefit from priming when target words were more abstractly related to their priming word. On the other hand, Rzezak et al. (2011) showed that children with temporal lobe epilepsy have impairments in functions related to tasks of SM, including word definition, sentence repetition, and category fluency.

The assessment of SM is complex as there is no single way to measure it. Among the tasks commonly used to assess it are semantic associations, semantic fluency, and the picture naming task (Martínez-Cuitiño \& Jaichenco, 2012). Some of the tests that are used for assessing SM include Wechsler Memory Scale-Revised (WMS-R; Spaan, 2016; Wechsler, 1987), the vocabulary subtest of the Wechsler Intelligence Scale (WISC; Lah \& Smith, 2014), the verbal fluency portion (animals and foods) of the Boston Naming Test (Kaplan et al., 1983; see also Smith \& Lah, 2011), and the Semantic and Episodic Memory Test (Vallet et al., 2017). However, some tasks may be considered more precise and sensitive than others by different authors. For example, according to Verma and Howard (2012), the naming task can account for subtler deficits and they consider fluency tasks to be more sensitive for the detection of semantic alterations. Furthermore, (Martínez-Cuitiño \& Jaichenco, 2012) note that in the evaluation of SM, the types of sensory information involved in their recovery must be taken into account because they may have consequences on performance. Tomasello et al. (2017) argue that learning of semantic relationships between words, objects, and actions leads to the gener- ation of distributed circuits that form the motor and visual brain regions representing specific object properties (e.g., color) and thus are not only modality specific but also property specific (Kiefer \& Pulvermüller, 2012; Martin, 2015). Consequently, SM assessment must be multimodal, that is, consider different sensory modalities (e.g., verbal, visual, and auditory) and multiple response modalities (e.g., written denomination, oral denomination, and drawing) by presenting predetermined stimuli in different forms (Pulvermüller, 2013).

Recently, Catricalà et al. (2013) developed a battery of six different SM tests to evaluate the state of an adult person at a conceptual and features level along different modalities (naming a colored picture, naming in response to an oral description, word-picture matching, picture sorting, free generation of features, and sentence verification). The authors included variables shown to influence performance on SM tests, such as the familiarity of the concepts or objects used (Funnel \& Sheridan, 1992), the semantic relevance of the stimuli used in the test (Sartori \& Lombardi, 2004), the semantic distinction of the stimuli (Cree \& McRae, 2003; Zannino et al., 2006), and the manipulability of the stimuli (Filliter et al., 2005). The psychometric properties of this instrument showed a significant correlation between the tests, with the exception of the word-picture matching test with picture sorting and free generation of features (Catricalà et al., 2013). The positive relationships found among tests suggest that they assess common aspects of SM, while also showing some differences related to specific tasks and application modalities (Catricalà et al., 2013).

Considering that only few studies assess SM in children and the need to implement scales that evaluate SM with an approach that includes both the conceptual and features level and different evaluation modalities on the same scale, the main goal of the present study is to explore the characteristics and study the feasibility of the battery developed by Catricalà et al. (2013) in a nonclinical sample of Colombian children. By doing this, more specific results could be obtained to ultimately contribute to improve diagnosis and treatment of SM alterations present in highly prevalent disorders in children, such as epilepsy, head injuries, ADHD, and autism.

\section{Subjects and Methods}

\subsection{Subjects}

This study was of a cross-sectional and exploratory types (Díaz Narváez, 2009; Hulley et al., 2007), being its main purpose to shed light on the feasibility of a recently proposed battery to assess SM in children, using a battery that had been previously proposed, validated, and applied in adults, which had not been previously described in another study (Sim \& Wright, 2002). 
Figure 1

Location of Barranquilla in South America (left). The Atlántico Department is located in the Northwestern region of Colombia (center). Barranquilla (right) has a population of $\sim 1.3$ million and is both the capital of the Atlántico Department and the largest city of the Caribbean Coast region of Colombia

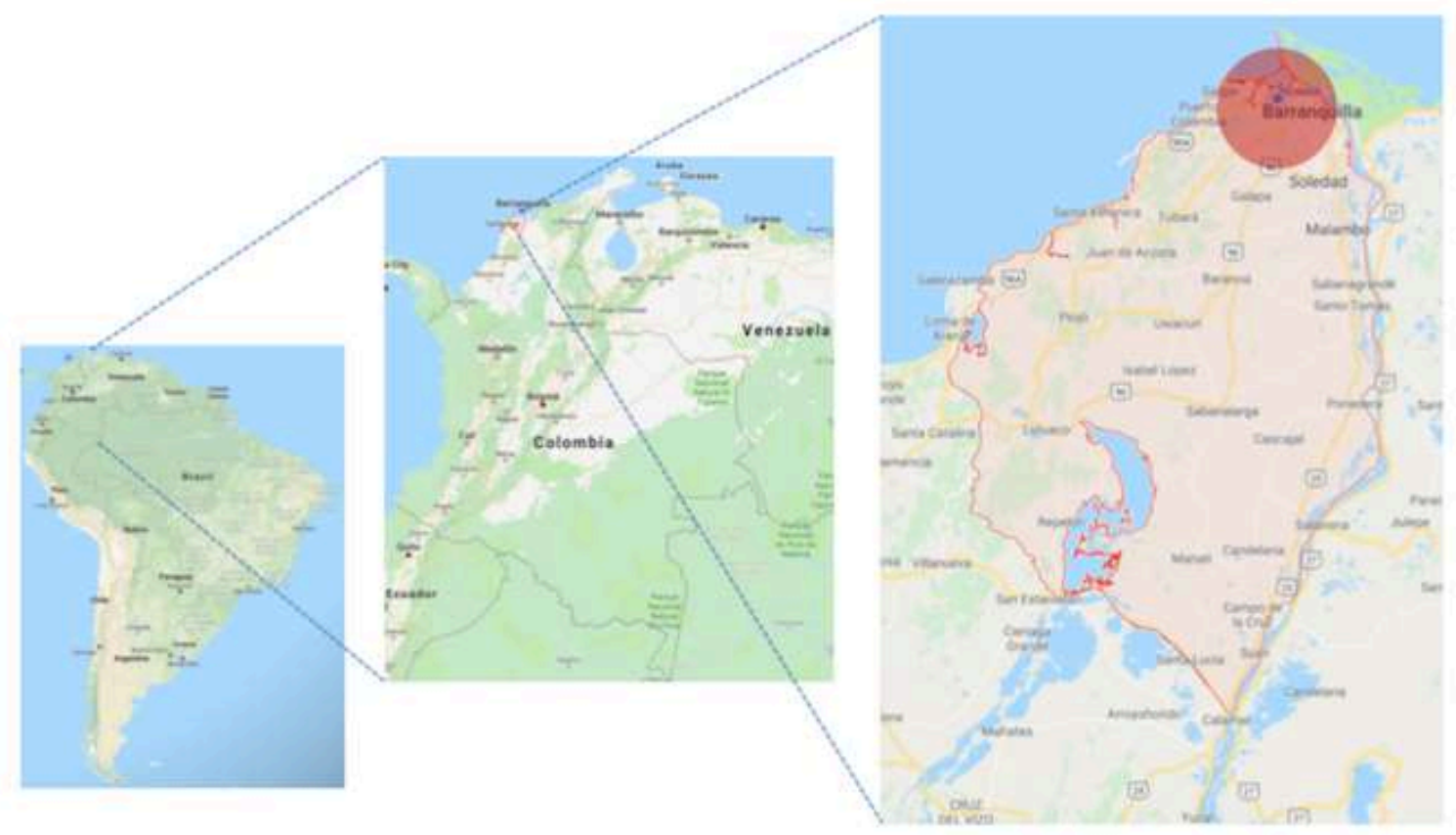

The sample was gender and aged-balanced, and consisted of 111 children (57 [51\%] boys, 44 [49\%] girls) aged $6(n=68[61 \%] ; 51 \%$ male) and $7(n=43[39 \%] ; 51 \%$ male) years old, enrolled in first and second grades in elementary schools and attending private and public institutions in the city of Barranquilla, Colombia. Barranquilla is the capital of the Atlántico Department, which is located on the Northern Colombian Caribbean coast (Figure 1), and its population is a mixture of Aboriginal Amerindian communities with Spaniards and Africans, with the later immigration of Syrians and Lebanese, Sephardi Jews, Germans, Italians, and English immigrants (Villalón, 2008; Wabgou et al., 2012).

Sample size was considered following the Catricalà et al. (2013) study, and taking a similar number of participants. Among the inclusion criteria, we have that children must be enrolled in public and private elementary schools in the city, and between 6 and 7 years old. Children with brain trauma or some type of diagnosed brain damage or mental disorder were excluded. The study was approved by the Direction of Research, Development and Innovation at Universidad del Norte, Barranquilla, Colombia (approval \# 2017-03). Before administering the tests, a parent or guardian responsible for each participant read and signed an informed consent describing the study and authorized the childs participation. Children also read and signed an assent form with the assistance of the evaluator. The study followed the principles outlined in the Declaration of Helsinki WMA 2013.

\subsection{Instruments}

\subsubsection{Kaufman Brief Intelligence Test (Kaufman \& Kaufman, 1990)}

The Kaufman Brief Intelligence Test (KBIT) measures general intelligence in children, adolescents, and adults (4 to 90 years old). This test was used to have a reliable measure of the intellectual level of the study children as a control variable. It includes two vocabulary subtests and one matrix subtest. According to the test guidelines and the age of the study participants, only one vocabulary test and the matrix subtest were applied. In the vocabulary test, the children observed images of different objects (e.g. bed, lamp) and had to answer the question "what is this?"

In the matrices subtest, children observed images with figures or matrices that always had a blank space that should be completed with another figure. Children should select which shape would best complete the sequence among some response options. The score for each question in both subtests ranges from 1 to 0 . The completed KBIT produces verbal, non-verbal, and composite IQs as a summary of overall performance on the test. Concurrent validity studies of the KBIT have been carried out with other instruments to evaluate intelligence, obtaining adequate results regarding the properties of the test Hays et al., 2002; Naugle et al., 1993; Prewett, 1995. 
Table 1

Demographic characteristics of the study population

\begin{tabular}{|c|c|c|c|c|}
\hline \multirow[b]{2}{*}{ Variable } & \multicolumn{2}{|c|}{ Median (MAD) [Range] } & \multirow[b]{2}{*}{$W$} & \multirow[b]{2}{*}{$p$} \\
\hline & $\begin{array}{l}\text { Female } \\
(n=54)\end{array}$ & $\begin{array}{c}\text { Male } \\
(n=57)\end{array}$ & & \\
\hline Age (years) & $6(0)[6-7]$ & $6(0)[6-7]$ & 1543.5 & .978 \\
\hline KBIT intellect & $110.5(13.3)[68-140]$ & $109(14.8)[91-141]$ & 1647 & .526 \\
\hline \multicolumn{5}{|l|}{ Semantic task } \\
\hline - Naming of colored photographs & $40.5(3.7)[31-46]$ & $40(4.4)[33-47]$ & 1812 & .106 \\
\hline - Naming in response to an oral description & $36(4.4)[26-48]$ & $37(4.4)[27-46]$ & 1437 & .548 \\
\hline - Word-picture matching test & $47(1.5)[40-48]$ & $47(1.5)[35-48]$ & 1416.5 & .458 \\
\hline - Picture sorting at four levels & $173.5(17)[83-192]$ & $172(19.3)[108-192]$ & 1556 & .922 \\
\hline - Free generation of features & $142(14.1)[77-258]$ & $141(32.6)[30-233]$ & 1689 & .378 \\
\hline - Sentence verification & $403(60)[48-478]$ & $413(35.6)[48-465]$ & 1532 & .969 \\
\hline
\end{tabular}

KBIT = Kauffman Brief Intelligence Test; MAD = median absolute deviation; $W=$ MannWhitney $U$ test statistic; $p=$ p-value.

\subsubsection{Italian battery for the assessment of semantic memory} We used a six-task battery proposed by Catricalà et al. (2013) to assess SM along different modalities. The instrument subtest are (1) naming a colored picture, (2) naming in response to an oral description, and (3) wordpicture matching task, (4) picture sorting, (5) free generation of features, as well as (6) sentence verification tasks. For examples of each category, review the Catricalà et al. paper 2013.

The battery features a common set of 48 stimuli with both living and unliving categories. It was translated from Italian to Spanish for the present study, in the following way. Initially, the authors revised the original scale so that materials/stimuli were suitable to children. Then, a certified bilingual Colombian translator of Italian descent, working at a private school in Barranquilla, performed the translation and cultural adaptation. Then, two of the authors reviewed the translated version and proposed minor changes that were implemented in a way approved of by the translator.

\subsection{Procedure}

Researchers scheduled an appointment with each child and a parent or a person responsible for them to explain the conditions of the study and provide the informed consent and assent forms.

After this, the parent/guardian left the child with the evaluator. Participants performed an intelligence test with two subtests that measured verbal and nonverbal intelligence and a SM battery with six subtests including different tasks. The intelligence test took about 20 minutes, and the SM battery took between 1 and 1.5 hours per participant. Halfway through the application of the second test, the researcher gave a rest period of no more than 10 minutes to each participant.

\subsection{Statistical analyses}

Robust statistics were used to describe and analyze the data (Field \& Wilcox, 2017). Statistical analyses and graphing were performed in $\mathrm{R}$ version 3.5.1 ( $\mathrm{R}$ Core Team, 2019). The median and the median absolute deviation (MAD) were used to estimate the location and scale of the data (Vélez \& Correa, 2014). Following the analytical approach used by Catricalà et al. (2013), robust linear regressions were fitted for each of the six subtests of the battery for the assessment of SM using the rlm function in the MASS package for R. The dependent variables were the test scores, and the independent variables were gender, age, and intelligence (as KBIT scores, continuous variables). Pearsons linear correlation coefficient and correlation networks were used to study the relationship among the six subtests.

\section{Results}

The descriptive total scores by gender for all six subtests of the SM battery are reported in Table 1 . Because of the balanced nature of our design, age distribution did not differ by gender ( $\chi^{2}=0$, degrees of freedom $[d f]=1, p>.05$; Figure 2a). However, we found an age effect on general intelligence after gender was corrected for $\left(F_{1,108}=5.307, p=.023\right)$. $\mathrm{R}$ code, data and materials/stimuli associated relevant to this study can be found online at figshare (https://bit.ly/2QYSAOZ).

Table 2 presents the summary statistics of the six subtests of the SM battery by age group. We found that the results for the word-picture matching test score differs statistically between children aged 6 years and children aged 7 years $(n=43 ; W=1056.5, p=.038)$. However, this result did not persist after correction for gender and age was performed (Figure 2a).

Results from the final multiple regression analysis are presented in Table 3. Age was found to be positively associated with naming of colored photographs $(\beta=.75$, 


\section{Figure 2}

(a) Mosaic plot representing the proportions of male and female children aged 6 and 7 years. The area of each tile is proportional to the number of observations within the given category. Similar areas of the tiles index a lack of an association between age and gender; tiles of similar size index a lack of significant statistical association; significant statistical association is likely to happen when tiles have pronounced different sizes (for details about this graphical method see (Hartigan \& Kleiner, 1984)). This indicates a balanced design. (b) Bean plots for the scores of each subtest of the battery assessing semantic memory by gender and age. The pink, blue, and dotted horizontal lines correspond, respectively, to the within gender/age average score, the individuals scores, and the global average over 111 children from Barranquilla, Colombia (Table 1). Here, $P_{a g e}, P_{\text {gender }}$, and $P_{I}$ refer to the p-value associated with the effect of age, gender, and their interaction on the scores, respectively.
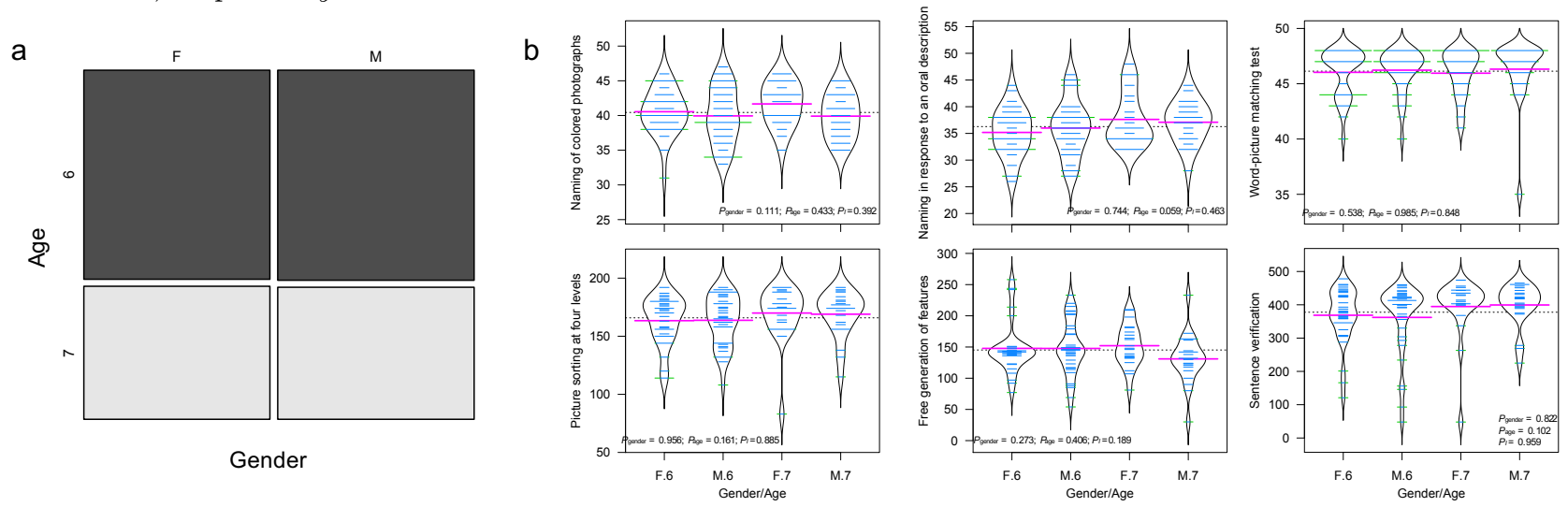

$p=.039)$, naming in response to an oral description $(\beta=$ $1.81, p=.039)$, picture sorting at four levels $(\beta=7.22$, $p=.029)$, and sentence verification $(\beta=26.66, p=.01)$.

Figure 3 displays the correlation network for the six tasks of the SM battery. We identified statistically significant, positive correlations between the tasks naming of colors photographs and naming in response to an oral description $(r=.561, p<.001)$, sentence verification and naming in response to an oral description $(r=.207, p<.01)$, and sentence verification and free generation of features $(r=.251, p<.01)$.

\section{Discussion}

This study explored the performance of Catricalà et al. (2013) semantic memory (SM) battery in a non-clinical sample of Colombian children. We found an age effect on general intelligence after gender was corrected for, and there was no difference found for the six subtests scores after gender and age were corrected for. On the other hand, the results of the final multiple regression analysis showed that age was positively associated with four of the SM tasks: naming of colored photographs, naming in response to an oral description, picture sorting at four levels, and sentence verification.

As shown in Table 3, the performance in each of the six tasks had participant's age, gender, and intellect scores as covariates. These covariates had different effects on each of the tasks (e.g. age had effects in 3 of the tasks and intellect in only one; in the other two tasks no effect emerged) and can be interpreted as follows. First, the 'Naming in response to an oral description', 'Picture sorting at four levels', and 'Sentence verification' tasks seem sensitive to subtle age differences (6 vs. 7 years old), under the premise that gender and intellect are kept fixed; and secondly, the 'Naming of coloured photographs' task is seemingly sensitive to intellect differences, when gender and age are kept fixed. These results are in line with previous studies assessing SM, which found similar relationships between some of these covariates and SM. For example, Doppelmayr et al. (2005) found that more intelligent people show more extensive activation in a semantic processing system, while Boman (2004) found that females outperformed males in SM tasks. Interestingly, Catricalà et al. (2013) found a significant difference in the free generation of features subtest in relation to participant gender.

The difference in the coefficients of the fitted models between Catricalà et al. (2013) requires further attention. Catricalà et al. (2013) reported much lower coefficients than the ones found in our study (naming of colored photographs subtest: $\beta=.755$ vs. $\beta=.101$; naming in response to an oral description: $\beta=1.818$ vs. $\beta=-.047$; sentence verification: $\beta=26.668$ vs. $\beta=.508)$. For picture sorting at four levels, we obtained $\beta=7.227$, but Catricalà et al. (2013) did not report a $\beta$ value for this subtest in their study.

Some differences in correlation levels were also found in the battery subtests. The original study found that 
Table 2

Summary statistics for the Italian Semantic Memory battery for the study population

\begin{tabular}{lcccc}
\hline \multirow{2}{*}{ Variable } & \multicolumn{2}{c}{ Median (MAD) [Range $]$} & & \\
\cline { 2 - 4 } & $\begin{array}{c}\mathbf{6} \text { years old } \\
(n=68)\end{array}$ & $\begin{array}{c}\mathbf{7} \text { years old } \\
(n=43)\end{array}$ & $W$ & \\
\hline KBIT intellect & $110.5(13.3)[90-141]$ & $108(13.3)[68-131]$ & 1767.5 & .065 \\
Semantic task & & & & \\
- Naming of colored photographs & $40(3)[31-47]$ & $41(3)[35-46]$ & 1345 & .479 \\
- Naming in response to an oral description & $36(4.4)[26-46]$ & $37(4.4)[28-48]$ & 1178.5 & .124 \\
- Word-picture matching test & $396(57.1)[93-478]$ & $416(40)[48-474]$ & 1056.5 & $\mathbf{. 0 3 8}$ \\
- Picture sorting at four levels & $142(23.7)[54-258]$ & $138.5(34.1)[30-233]$ & 1487 & .526 \\
- Free generation of features & $170(20.8)[108-192]$ & $174(19.3)[83-192]$ & 1088.5 & .125 \\
- Sentence verification & $47(1.5)[40-48]$ & $47(1.5)[35-48]$ & 1384 & .629 \\
\hline
\end{tabular}

KBIT $=$ Kauffman Brief Intelligence Test; MAD = median absolute deviation; $W=$ MannWhitney $U$ test statistic; $p=$ p-value. Statistically significant differences at $5 \%$ are shown in bold.

Table 3

Significant predictors models for the six task

\begin{tabular}{lccc}
\hline Semantic task & $\begin{array}{c}\text { Independent } \\
\text { variables }\end{array}$ & $\begin{array}{c}\text { Regression } \\
\text { Coefficient } \\
(\beta)\end{array}$ & $p$ \\
\hline \multirow{2}{*}{ Naming of colored photographs } & & .755 & .158 \\
& Age & -1.144 & .056 \\
Naming in response to an oral description & Gender (male) & .049 & $\mathbf{. 0 3 9}$ \\
\cline { 2 - 4 } & Intellect & 1.818 & $\mathbf{. 0 3 4}$ \\
& Age & .441 & .320 \\
Wordpicture matching test & Gender (male) & .039 & $\mathbf{. 1 4 0}$ \\
\cline { 2 - 4 } & Intellect & .113 & .383 \\
Picture sorting at four levels & Age & .348 & .167 \\
& Gender (male) & -.005 & .358 \\
\cline { 2 - 4 } Free generation of features & Intellect & 7.227 & $\mathbf{. 0 2 9}$ \\
& Age & -.973 & .393 \\
Sentence verification & Gender (male) & .094 & .250 \\
\cline { 2 - 4 } & Intellect & -.585 & .467 \\
& Age & -5.236 & .218 \\
& Gender (male) & .298 & .125 \\
\cline { 2 - 4 } & Intellect & 26.668 &. $\mathbf{0 1 0}$ \\
& Age & 5.529 & .305 \\
\hline
\end{tabular}

$p=$ p-value. Statistically significant differences at $5 \%$ are shown in bold. Gender and intellect were used a covariate in all regression models.

all subtests were significantly correlated except for the two pairs: first, picture sorting at four levels and wordpicture matching, and second, free generation of features and word-picture matching. In our present study assessing SM in nonclinical sample of children there were significant correlations between the following pairs of subtests: naming of colored photographs and naming in response to an oral description, naming in response to an oral description and sentence verification, and sentence verification and free generation of features (Figure 3).
The low scores in the free generation of features subtest could be due to the population and the nature of the task. The spontaneous expression of the features of objects without clues requires knowledge of the objects and familiarity with them, that is, it depends on semantic content and vocabulary, which increase with age as new things are learned throughout life. According to Verhaeghen (2003) and Owens (2015), differences in vocabulary size between children and adults continue over ones life. 


\section{Figure 3}

Correlation network for the Semantic Memory test in 111 children from Barranquilla, Colombia. The green and red lines between pairs of nodes represent positive and negative correlations, respectively. Statistically significant correlations at 5\% are shown in orange. The nodes indicate 1 , naming of colored photographs; 2, naming in response to an oral description: 3, sentence verification; 4, free generation of features; 5 , picture sorting at four levels; and 6 , wordpicture matching test.

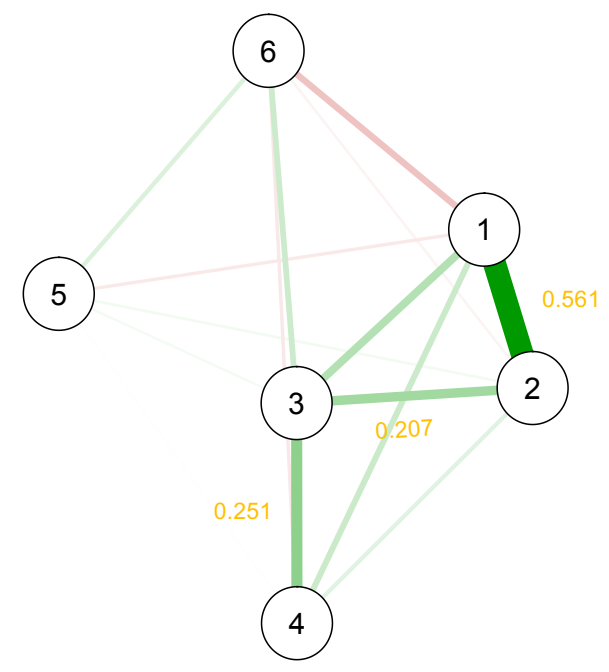

Moreover, the evident differences of the education levels for the study populations have implications for vocabulary skills (Martino \& Hoffman, 2002; Zechmeister et al., 1995). The population of our study had a significantly (lower) level of education from that in Catricalà et al. (2013), and presumably this difference was reflected in tasks performances. Additionally, vocabulary and experience with the world are the basis for other processes related to SM, including reading comprehension (Stahl \& Nagy, 2006) and phonological working memory (Gathercole \& Baddeley, 1989), and are related to language achievements (Marchman \& Fernald, 2008; Monaco et al., 2019). Given that early age interactions with the world are essential to the consolidation of concepts, we argue that this battery may help in measuring healthy (i.e., normal) versus non-healthy SM development versus non-healthy development. Furthermore, considering that low variability was observed in 6-yearold girls in the free generation of features subtest, we suggest that additional studies need to be conducted with this instrument in a population of children of other nationalities with similar sample characteristics to compare their performances and determine whether this is limited to our data group.

Although the scope of the present study was purely exploratory and we sought to assess the characteristics and performance (in a population of nonclinical children) of a complete battery for the evaluation of SM that was originally developed and applied in adults, our results may have real and interesting implications for the evaluation of SM and language skills, not only in control children but also in children with some degree of intellectual disability or other challenges related to this set of skills, such as epilepsy (Smith \& Lah, 2011), mesial temporal sclerosis (Rzezak et al., 2011), head injury (Hanten \& Martin, 2000), and other neurodevelopmental disorders like ADHD (Egeland et al., 2010; Krauel et al., 2009) and autism (Bowler et al., 2014; Massand \& Bowler, 2013). Despite finding that using the translated version of the battery in this population is feasible, more studies of similar nature with a larger sample are needed in the same population to rule out potential biases at the sample level. It is also important to constrain study inferences or results based on the specific study sample to clearly delimit the work of other researchers who intend to replicate it, both with a similar sample and with other types to allow for significant and differential contributions to the construction of knowledge (Simons et al., 2017). The characteristics and psychometric properties of this SM battery in clinical samples are yet to be explored. Thus, over-generalization of the results can be limited.

Despite our encouraging results, some limitations of our study need to be acknowledged. First, due to the narrow age range we used, it is not possible to draw conclusions or generalize the results to childhood as a whole. Secondly, because this was not a validation of the instrument but an exploration of its characteristics in a sample of nonclinical children, a very large sample size was not necessary, and the sample size of the original study was taken as a guide. It would be interesting to see the results of the battery for different age ranges, taking into account the different stages of cognitive and SM development and expand the study sample to determine the batterys psychometric properties. Likewise, the range of KBIT in the female group was large. Future studies should correlate the range of the KBIT and the associated IQ classifications. It is also important to contemplate a more robust process of contextual adaptation after translation than that used in the present study.

In conclusion, our exploratory study shows that using the Spanish translation of the (Catricalà et al., 2013) battery is feasible to assess SM in children with a nonclinical condition. As studies assessing SM in children are scarce, this is the first attempt to expand this battery, originally developed, applied and validated on adult population, to other age groups. Thus, starting by an age group is considered a contribution to the advancement of research in this field, especially when the instrument used includes several response modalities (Pulvermüller, 2013). 


\section{Acknowledgments}

We thank all individuals participating in this study for their cooperation, disposition, and patience. M.C.N.S. is a doctoral student at Universidad del Norte. She received financial support from the Colombian Agency for Research and Development (COLCIENCIAS), contract FP44842-119-2017. Some of this work is to be presented in partial fulfillment of the requirements for the $\mathrm{PhD}$ degree. The sponsors of the study had no role in study design, data collection, data analysis, data interpretation, or writing of the paper. The authors assert that all procedures contributing to this work have been performed in accordance with the ethical standards laid down in the 1964 Declaration of Helsinki and its later amendments.

\section{References}

Antonucci, S. M., \& Reilly, J. (2008). Semantic memory and language processing: A primer. Seminars in Speech and Language, 29, 5-17. https://doi.org/ 10.1055/s-2008-1061621.

Bauera, P. J., Espositob, A. G., \& Daly, J. J. (2020). Self-derivation through memory integration: A model for accumulation of semantic knowledge. Learning and Instruction, 66, 101271. https:// doi.org/10.1016/j.learninstruc.2019.101271.

Boman, E. (2004). The effects of noise and gender on children s episodic and. Scandinavian Journal of Psychology, 45(5), 407-416. https://doi.org/ 10.1111/j.1467-9450.2004.00422.x.

Bowler, D. M., Gaigg, S. B., \& Gardiner, J. M. (2014). Binding of multiple features in memory by highfunctioning adults with autism spectrum disorder. Journal of Autism and Developmental Disorders, 44 (9), 2355-2362. https://dx.doi.org/ 10.1007/s10803-014-2105-y.

Bozeat, S., Lambon, M., R, Patterson, K., Garrard, P., \& Hodges, J. (2000). Non-verbal semantic impairment in semantic dementia. Neuropsychologia, 38 (9), 1207-15. https://doi.org/10.1016/s 0028-3932(00)00034-8.

Catricalà, E., Della Rosa, P. A., Ginex, V., Mussetti, Z., Plebani, V., \& Cappa, S. F. (2013). An italian battery for the assessment of semantic memory disorders. Neurological Sciences, 34(6), 985-993. https://doi.org/10.1007/s10072-012-1181-z.

Cree, G. S., \& McRae, K. (2003). Analyzing the factors underlying the structure and computation of the meaning of chipmunk, cherry, chisel, cheese, and cello (and many other such concrete nouns). Journal of Experimental Psychology, 132(2), 163201. https://doi.org/10.1037/0096-3445.132.2.163.

De Vega, M. (2007). Introducción a la psicología cognitiva. Alianza.

Díaz Narváez, P., V. (2009). Metodología de la investigación científica y bioestadística: para médicos, odontólogos y estudiantes de ciencias de la salud (Second edition). RIL Editores.

Diges, M., \& Perpiñá, C. (2008). Psicopatología de la memoria. In A. Belloch, B. Sandín, \& F. Ramos (Eds.), Manual de psicopatología (Rev. ed., Vol. 1) (pp. 169-204). McGraw-Hill.

Doppelmayr, M., Klimesch, W., Hodlmoser, K., Sauseng, P., \& Gruber, W. (2005). Intelligence related upper alpha desynchronization in a semantic memory task. Brain Research Bulletin, 66(2), 171-177. https://doi.org/10.1016/j.brainresbull. 2005.04.007.

Egeland, J., Johansen, S. N., \& Ueland, T. (2010). Do low-effort learning strategies mediate impaired memory in ADHD? Journal of learning disanilities, 43(5), 430-440. https://doi.org/10.1177 $\% 2 \mathrm{~F} 0022219409355473$.

Field, A., \& Wilcox, R. (2017). Robust statistical methods: A primer for clinical psychology and experimental psychopathology researchers. Behavior Research and Therapy, 98, 19-38. https:// doi.org/10.1016/j.brat.2017.05.013.

Filliter, J. H., McMullen, P. A., \& Westwood, D. (2005). Manipulability and living/non-living category effects on object identification. Brain Cognition, 57(1), 61-65. https://doi.org/10.1016/j.bandc. 2004.08.022.

Funnel, E., \& Sheridan, J. (1992). Categories of knowledge? unfamiliar aspects of living and non-living things. Cognitive Neuropsychology, 9(2), 135153. https://doi.org/10.1080/02643299208252056.

Garrido, P., Martínez, F. J., Barrachina, J. P., Baldassarri, S., Cerezo, E., \& Serón Arbeola, F. J. (2018). Learning through embodied conversational agents with semantic memory. The International Journal of engineering education, 34(2), 442-457.

Gathercole, S. E., \& Baddeley, A. D. (1989). Evaluation of the role of phonological stm in the development of vocabulary in children: A longitudinal study. Journal of Memory and Language, 28(2), 200-213. https://doi.org/10.1016/0749596X(89)90044-2.

Gaye Vaurio, R. (2004). The Structure and Function of Semantic Memory in Children with AttentionDeficit/Hyperactivity Disorder [Doctoral dissertation, The University of Texas, Austin]. https:/ / search.proquest.com/openview/1901a243249a2 cb53383d8a0f6a4e0dd/1?pq-origsite=gscholar\& $\mathrm{cbl}=18750 \&$ diss $=\mathrm{y}$.

Hanten, G., \& Martin, R. C. (2000). Contributions of phonological and semantic short-term memory to sentence processing: Evidence from two cases of closed head injury in children. Journal of Memory and Language, 43(2), 335-361. https:// doi.org/10.1006/jmla.2000.2731. 
Hartigan, J. A., \& Kleiner, B. (1984). A Mosaic of Television Ratings. The American Statistician, 38(1), 32-35. https://doi.org/10.2307/2683556.

Hays, J. R., Reas, D. L., \& Shaw, J. B. (2002). Concurrent Validity of the Wechsler Abbreviated Scale of Intelligence and the Kaufman Brief Intelligence Test among Psychiatric Inpatients. Psychological Reports, 90(2), 355-359. https://doi. org/10.2466/pr0.2002.90.2.355.

Hulley, S. B., Cummings, S. R., Browner, W. S., Grady, D. G., \& Newman, T. B. (2007). Designing clinical reseach (3rd ed.). Wolters Kluwer.

Kaplan, E., Goodglass, H., \& Weintraub, S. (1983). Boston naming test. Lea, Philadelphia, Febiger.

Kiefer, M., \& Pulvermüller, F. (2012). Conceptual representations in mind and brain: Theoretical developments, current evidence and future directions. Cortex, 48(7), 805-825. https://doi.org/10.1016 /j.cortex.2011.04.006.

Krauel, K., Duzel, E., Hinrichs, H., Lenz, D., Herrmann, C. S., Santel, S., \& Baving, L. (2009). Electrophysiological correlates of semantic processing during encoding of neutral and emotional pictures in patients with adhd. Neuropsychologia, 47(8-9), 1873-1882. https://doi.org/10.1016/j. neuropsychologia.2009.02.030.

Lah, S., \& Smith, M. L. (2014). Semantic and episodic memory in children with temporal lobe epilepsy: Do they relate to literacy skills? Neuropsychology, 28(1), 113-122. https://doi.org/10.1037/ne u0000029.

Marchman, V. A., \& Fernald, A. (2008). Speed of word recognition and vocabulary knowledge in infancy predict cognitive and language outcomes in later childhood. Developmental Science, 11(3), F9F16. https://doi.org/10.1111/j.1467-7687.2008. 00671.x.

Martin, A. (2015). GRAPES-Grounding representations in action, perception, and emotion systems: How object properties and categories are represented in the human brain. Psychonomic Bulletin and Review, 23(4), 979-990. https://dx.doi.org/10.3 758\%2Fs13423-015-0842-3.

Martínez-Cuitiño, M., \& Jaichenco, V. (2012). Evaluación de la memoria semántica. Revista de Psicología, 8(16), 7-23. http://bibliotecadigital.uca. edu.ar/repositorio/revistas/evaluacion-memoriasemantica-cuitino-jaichenco.pdf.

Martino, N. L., \& Hoffman, P. R. (2002). An investigation of reading and language abilities of college freshmen. Journal of Research in Reading, 25(3), 310-318. https://doi.org/10.1111/14679817.00178 .

Massand, E., \& Bowler, D. M. (2013). Atypical neurophysiology underlying episodic and semantic memory in adults with autism spectrum disor- der. Journal of Autism and Developmental Disorders, 45(2), 298-315. https://doi.org/10.1007 /s10803-013-1869-9.

Monaco, E., Jost, L. B., Gygax, P. M., \& Annoni, J.-M. (2019). Embodied semantics in a second language: Critical review and clinical implications. Frontiers in Human Neuroscience, 13, Article 110. https://doi.org/10.3389/fnhum.2019.00110.

Naugle, R. I., Chelune, G. J., \& Tucker, G. D. (1993). Validity of the Kaufman Brief Intelligence Test. Psychological Assessment, 5(2), 182-186. https: //doi.org/10.1037/1040-3590.5.2.182.

Owens, R. E. (2015). Language development: An introduction (9th ed.). Pearson.

Portin, R., Laatu, S., Revonsuo, A., \& Rinne, U. (2000). Impairment of semantic knowledge in parkinson's disease. Archives of Neurology, 57(9), 133843. https://doi.org/10.1001/archneur.57.9.1338.

Prewett, P. N. (1995). A comparison of two screening tests (the Matrix Analogies Test-Short Form and the Kaufman Brief Intelligence Test) with the WISC-III. Psychological Assessment, 7(1), 69-72. https://doi.org/10.1037/1040-3590.7.1.69.

Pulvermüller, F. (2013). Semantic embodiment, disembodiment or misembodiment? in search of meaning in modules and neuron circuits. Brain and Language, 127(1), 86-103. https://doi.org/10.10 16/j.bandl.2013.05.015.

R Core Team. (2019). R: A language and environment for statistical computing. R Foundation for Statistical Computing. https://www.R-project.org/.

Robertson, E. K., \& Kohler, S. (2007). Insights from child development on the relationship between episodic and semantic memory. Neuropsychologia, 45(14), 3178-3189. https://doi.org/10.1016 /j.neuropsychologia.2007.06.021.

Rzezak, P., Guimarães, C., Fuentes, D., Guerreiro, M. M., \& Valente, K. D. R. (2011). Episodic and semantic memory in children with mesial temporal sclerosis. Epilepsy and Behavior, 21(3), 242247. https://doi.org/10.1016/j.yebeh.2011.03.032.

Sartori, G., \& Lombardi, L. (2004). Semantic relevance and semantic disorders. Journal of Cognitive Neuroscience, 16 (3), 439-452. https://doi.org/10. 1162/089892904322926773.

Sim, J., \& Wright, C. (2002). Research in health care: Concepts, designs and methods. Nelson Thornes Ltd.

Simons, D. J., Shoda, Y., \& Lindsay, D. S. (2017). Constraints on generality (COG): A proposed addition to all empirical papers. Perspectives on Psychological Science, 12(6), 1123-1128. https:// doi.org/10.1177\%2F1745691617708630.

Smith, M. L., \& Lah, S. (2011). One declarative memory system or two? the relationship between episodic and semantic memory in children with temporal 
lobe epilepsy. Neuropsychology, 25(5), 634-644. https://doi.org/10.1037/a0023770.

Spaan, P. E. J. (2016). Episodic and semantic memory impairments in (very) early alzheimers disease: The diagnostic accuracy of paired-associate learning formats. Cogent Psychology, 3(1), 1-25. https://doi.org/10.1080/23311908.2015.1125076.

Stahl, S. A., \& Nagy, M. E. (2006). Teaching word meanings. Lawrence Erlbaum.

Tomasello, R., Garagnani, M., Wennekers, T., \& Pulvermüller, F. (2017). Brain connections of words, perceptions and actions: A neurobiological model of spatio-temporal semantic activation in the human cortex. Neuropsychologia, 98, 111-129. https://doi.org/10.1016/j.neuropsychologia.2016. 07.004 .

Tulving, E. (1972). Episodic and semantic memory. In E. Tulving \& W. Donaldson (Eds.), Organization of memory (pp. 381403). Academic Press.

Tulving, E. (1983). Elements of episodic memory. Clarendon Press.

Tulving, E. (1985). How many memory systems are there? American Psychologist, 40(4), 385-398.

Tulving, E., \& Craik, F. M. I. (2000). The Oxford handbook of memory. Oxford University Press.

Vallet, G. T., Hudon, C., Bier, N., Macoir, J., \& Versace, R. (2017). A SEMantic and EPisodic memory test (SEMEP) developed within the embodied cognition framework: application to normal aging, Alzheimers disease and semantic dementia. Frontiers in Psychology, 8, 1493. https://doi.org/ 10.3389/fpsyg.2017.01493.

Vélez, J. I., \& Correa, J. C. (2014). Should we think of a different median estimator? Comunicaciones en Estadística, 7(1), 11-17.

Verhaeghen, P. (2003). Aging and vocabulary scores: A meta-analysis. Psychology and Aging, 18(2), 332-339. https://doi.org/10.1037/0882-7974.18.2.332.

Verma, M., \& Howard, R. J. (2012). Semantic memory and language dysfunction in early Alzheimers disease: A review. International Journal of Geriatric Psychiatry, 27(12), 1209-1217. https:// doi.org/10.1002/gps.3766.

Villalón, J. (2008). Colonias extranjeras en Barranquilla. Ediciones Uninorte.

Wabgou, M., Vargas, D., \& Carabalí, J. (2012). Las migraciones internacionales en Colombia. Investigación \&3 Desarrollo, 20(1). http://rcientificas. uninorte.edu.co/index.php/investigacion/article/ viewArticle/2116/3678.

Wang, W., Tan, A.-H., \& Teow, L.-N. (2017). Semantic Memory Modeling and Memory Interaction in Learning Agents. IEEE Transactions on Systems, Man, and Cybernetics: Systems, 47(11),
2882-2895. https://doi.org/10.1109/TSMC.2016. 2531683.

Wechsler, D. A. (1987). Wechsler Memory Scale-Revised. (Span, 2016). TX: Psychological Corporation.

World Medical Association. (2013). Ethical principles for medical research involving human subjects. Journal of the American Medical Association, 310(20), 2191-2194.

Zannino, G. D., Perri, R., Pasqualetti, P., Caltagirone, C., \& Carlesimo, G. A. (2006). (Category-specific) semantic deficits in Alzheimers patients: The role of semantic distance. Neuropsychologia, 44 (1), 52-61. https://doi.org/10.1016/j.neuropsychologia.2005.04.008.

Zechmeister, E. B., Chronis, A. M., Cull, W. L., DAnna, C. A., \& Healy, N. A. (1995). Growth of a functionally important lexicon. Journal of Reading Behavior, 27(2), 201-212. https://doi.org/10.10 $80 \% 2$ F10862969509547878. 